Revista Tecné, Episteme y Didaxis: TED. Año 2014, Número Extraordinario. ISSN Impreso: 0121-3814, ISSN web: 2323-0126

Memorias, Sexto Congreso Internacional sobre Formación de Profesores de Ciencias. 08 al 10 de octubre de 2014, Bogotá

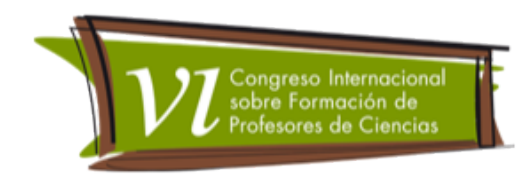

\title{
A formação inicial para o Ensino de Ciências e a Educação Inclusiva: o currículo das licenciaturas
}

Basso, Sabrina Pereira Soares'; Campos, Luciana Maria Lunardi²

Categoria 2. Trabalho de investigação

\section{Resumo}

O objetivo do trabalho foi analisar a inserção da temática Educação Inclusiva (El) em cursos de licenciatura da área de Ciências (Biologia, Física e Química), das universidades públicas estaduais do estado de São Paulo. Analisou-se o projeto políticos pedagógicos (PPP) e planos de ensino das disciplinas da área pedagógica, através da análise documental. Dos PPPs das licenciaturas em Ciências, apenas um curso de Física (FIS 4), um de Química (QUIM 6) e Ciências Biológicas (BIO 13) tratam da El. Em relação às disciplinas que abordam a El, dos 13 cursos de licenciatura em Ciências Biológicas, apenas três apresentam disciplinas que abordam a temática. Dos nove cursos de licenciatura em Física, quatro possuem disciplina que abordam a temática. Dos oito cursos de licenciatura em Química, dois contam com disciplinas que abordam a temática "Educação Inclusiva".

\section{Palavras-chaves}

Formação Inicial; Ensino de Ciências; Educação Inclusiva.

\section{Objetivo}

O objetivo foi analisar a inserção da temática Educação Inclusiva em cursos de formação inicial de professores da área de Ciências (Biologia, Física e Química), das universidades públicas estaduais do estado de São Paulo.

1 - Programa de Pós-graduação em Educação para a Ciência, Faculdade de Ciências, UNESP/Bauru, e-mail: soaresbasso@gmail.com

2 - Departamento de Educação, Instituto de Biociências, UNESP/Botucatu, e-mail: camposml@ibb.unesp.br 
Revista Tecné, Episteme y Didaxis: TED. Año 2014, Número Extraordinario. ISSN Impreso: 0121-3814, ISSN web: 2323-0126

Memorias, Sexto Congreso Internacional sobre Formación de Profesores de Ciencias. 08 al 10 de octubre de 2014, Bogotá

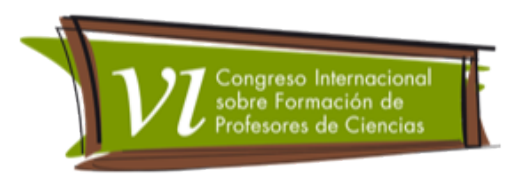

\section{Marco Teórico}

A temática da educação inclusiva está cada vez mais presente nas discussões acadêmicas atuais, sobretudo no que se refere à escolarização de pessoas com necessidades educacionais especiais (NEE - pessoas com deficiência intelectual, auditiva, visual, física, transtornos globais do desenvolvimento e altas habilidades/superdotação). No entanto, a educação inclusiva está na pauta da legislação brasileira desde meados da década de 90 (Prieto, 2006, pág.33).

Com a Declaração Mundial de Educação para Todos (Brasil, 1990) e a Declaração de Salamanca (Brasil, 1994a), o Brasil fez opção pela construção de um sistema educacional inclusivo em que alunos que "possuem condições de acompanhar e desenvolver as atividades curriculares programadas do ensino comum, no mesmo ritmo que os alunos ditos normais" (Brasil, 1994b, pág.19) terão acesso às classes comuns do ensino regular. Logo, a "educação tem hoje (...) um grande desafio: garantir o acesso aos conteúdos básicos que a escolarização deve proporcionar a todos os indivíduos - inclusive àqueles com necessidades educacionais especiais." (Brasil, 2001, pág.21).

Aliada a esses documentos, a Política Nacional de Educação Especial na Perspectiva da Educação Inclusiva (Brasil, 2008, pág.1), traz a garantia de formação de professores para o atendimento educacional especializado e demais profissionais da educação para a inclusão escolar.

De acordo com Rinaldi et al (2009):

O professor em sala de aula é peça fundamental para que a ação educativa direcionada aos alunos com necessidades educacionais especiais tenha margem para razoável sucesso. Assim, tanto a formação inicial quanto o apoio contínuo ao professor em seu contexto de trabalho devem englobar conceitos e prática pedagógica que criem as condições para uma educação coerente com o projeto inclusivo (Rinaldi et al., 2009, pág.152).

Aliada à fala de Rinaldi et al (2009). Mizukami (2010, pág.22) destaca que a formação inicial é a base para a construção do conhecimento pedagógico especializado, tendo uma grande importância na formação dos licenciandos.

Portanto, torna-se necessário que a discussão sobre a educação inclusiva seja iniciada durante a formação inicial dos licenciandos. 
Revista Tecné, Episteme y Didaxis: TED. Año 2014, Número Extraordinario. ISSN Impreso: 0121-3814, ISSN web: 2323-0126

Memorias, Sexto Congreso Internacional sobre Formación de Profesores de Ciencias. 08 al 10 de octubre de 2014, Bogotá

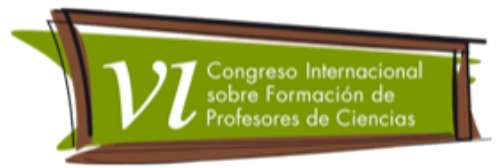

De acordo com o censo escolar (INEP, 2013), entre os anos de 2011 e 2012, o número de matrículas de alunos com NEE nos anos finais do ensino fundamental aumentou em 18\%, e no ensino médio, 27\%. Logo, professores de Ensino de Ciências (Biologia, Física e Química) e Matemática estão cada vez mais se deparando com os chamados "alunos de inclusão".

Neste cenário, surge questionamento sobre como a formação do professor de Ciências está acontecendo para atender aos alunos com necessidades educacionais especiais, mais especificamente aos alunos com deficiência.

Como resultado da democratização da ciência e de seus aparatos tecnológicos na vida humana, o ensino de ciências passa a ser considerado de crucial importância, já que o cidadão necessita, cotidianamente, tomar decisões que envolvam assuntos científicos (SANTOS, SCHNNETZLER, 2003; FENSHAM, 2002). A importância do estudo de ciências deve-se, sobretudo, ao fato de possibilitar, à pessoa, o desenvolvimento de uma visão crítica sobre a realidade que a cerca, podendo, assim, utilizar seu conhecimento adquirido no cotidiano, analisar diferentes situações e ter condições para avaliar assuntos de importância na determinação de sua qualidade de vida. (Vilela-Ribeiro \& Benite, 2010, pág.587).

Nesse contexto, realizamos a investigação aqui apresentada.

\section{Metodologia}

O presente trabalho tem por objeto de estudo os cursos de licenciatura em Ciências (Biologia, Física e Química) das universidades públicas estaduais do estado de São Paulo, sendo: Universidade de São Paulo (USP); Universidade Estadual de Campinas (Unicamp); Universidade Estadual Paulista "Júlio de Mesquista Filho" (UNESP) (Tabela 1).

Tabela 1: Relação os cursos de licenciatura em Ciências das universidades públicas estaduais do estado de São Paulo

\begin{tabular}{|l|l|l|l|}
\hline & \multicolumn{3}{|c|}{ Universidade } \\
\hline Curso & UNESP & UNICAMP & USP \\
\hline Ciências Biológicas & $1,2,3,4,5,6,7$ e 8 & 1 & $1,2,3$ \\
\hline
\end{tabular}


Revista Tecné, Episteme y Didaxis: TED. Año 2014, Número Extraordinario. ISSN Impreso: 0121-3814, ISSN web: 2323-0126

Memorias, Sexto Congreso Internacional sobre Formación de Profesores de Ciencias. 08 al 10 de octubre de 2014, Bogotá

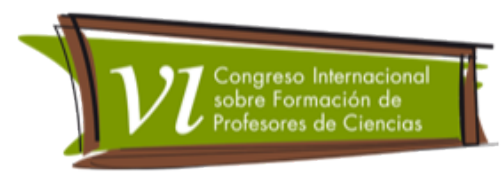

\begin{tabular}{|c|c|c|c|}
\hline Física & $1,2,3,4,5$ e 6 & 1 & 1 \\
\hline Química & $1,2,3,4$ & 1 & 1,2 \\
\hline $\begin{array}{l}\text { Ciências Exatas } \\
\text { com habilitação em Q }\end{array}$ & - & - & 1 \\
\hline $\begin{array}{l}\text { Ciências Exatas } \\
\text { com habilitação em Fís }\end{array}$ & - & - & 1 \\
\hline Ciências da Natureza & - & - & 1 \\
\hline
\end{tabular}

Os dados foram obtidos pela análise de dois documentos: 1) projeto político pedagógico (PPP); e 2) planos de ensino (PE) das disciplinas da área pedagógica oferecidas nesses cursos.

Para a análise do PPP e dos PE, optou-se pela análise documental, compreendendo-se que "os documentos [...] representam ainda uma fonte "natural" de informação" e que "[...] a análise documental indica problemas que devem ser mais bem explorados através de outros métodos" (Lüdke \& André, 1986, pág. 39). Foram buscadas as seguintes palavras chaves: educação inclusiva, inclusão escolar, educação especial, alunos com necessidades educacionais especiais, deficiência, deficientes e recursos especiais.

Nos PPPs, as palavras chaves listadas acima foram buscadas no documento todo. Já nos PEs, as palavras chaves foram procuradas nos títulos, objetivos e conteúdos programáticos.

Os cursos foram identificados usando a sigla BIO (Ciências Biológicas e Ciências da Natureza - Quadro 1), FIS (Física e Ciências Exatas com habilitação em Física Quadro 2) e QUIM (Química e Ciências Exatas com habilitação em Química Quadro 3). A ordem nos quadros não corresponde à ordem das universidades apresentadas na Tabela 1. 
Revista Tecné, Episteme y Didaxis: TED. Año 2014, Número Extraordinario. ISSN Impreso: 0121-3814, ISSN web: 2323-0126

Memorias, Sexto Congreso Internacional sobre Formación de Profesores de Ciencias. 08 al 10 de octubre de 2014, Bogotá

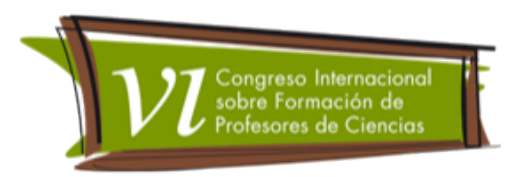

\section{Resultados}

Dos PPPs dos cursos de licenciatura em Ciências, apenas os documentos dos cursos de Física (FIS 4), de Química (QUIM 6) e Ciências Biológica (BIO 13) é que tratam da Educação Inclusiva.

No caso do PPP de Física, trata-se de um documento referente ao plano de trabalho do estágio supervisionado. Já no PPP da Química, há vários trechos que abordam a temática da Educação Inclusiva, como o excerto abaixo:

Devido à preocupação da CoC com a formação do licenciando que atuará em escolas onde estudam alunos com necessidades especiais, vêm sendo implementados no curso projetos voltados para Educação Especial e Inclusiva, realizados em 2006-2007, no qual os alunos estagiam em escolas que possuam alunos incluídos e em espaços de educação não-formais. Além disso, está sendo incluída no curso uma disciplina obrigatória que contempla o conteúdo de LIBRAS (Língua Brasileira de Sinais), que visa atender também a determinações legais do MEC (Lei 10435/02 e Decreto 5626/05). (QUIM 6, 2013, pág. 32).

O PPP do curso BIO 13 aborda a temática ao discutir a "Formação docente voltada para a promoção de mudanças curriculares efetivas" (BIO 13, 2013, pág.07) e quando discute a "Iniciação à licenciatura" (BIO 13, 2013, pág.16).

Ressaltamos que em nenhum desses PPPs citados a Educação Inclusiva é amplamente debatida. De um modo geral, ela é apenas citada como parte do planejamento de algumas ações educativas referentes ao curso de licenciatura.

Em relação às disciplinas que abordam a temática da Educação Inclusiva, no $2^{\circ}$. semestre de 2013, os cursos de licenciatura de nove unidades da UNESP, ofertaram $\circ$ curso de Língua Brasileira de Sinais (Libras) à distância (http://www.unesp.br/portal\#!/noticia/1 1787/cursos-de-graduacao-da-unespoferecem-a-disciplina-libras/), não estando presente no PPP dos cursos desses campi e na grade curricular disponível no site desses cursos, não sendo contabilizado no Quadro 1.

Dos 13 cursos de licenciatura em Ciências Biológicas, apenas quatro apresentam disciplinas que abordam a temática "Educação Inclusiva", sendo que em BIO 3, a 
Revista Tecné, Episteme y Didaxis: TED. Año 2014, Número Extraordinario. ISSN Impreso: 0121-3814, ISSN web: 2323-0126

Memorias, Sexto Congreso Internacional sobre Formación de Profesores de Ciencias. 08 al 10 de octubre de 2014, Bogotá

disciplina é optativa, e em BIO 10, BIO 11 e BIO 13, a disciplina é obrigatória (Quadro 01).

Quadro 01: Relação da oferta de disciplinas com a temática "Educação Inclusiva" nos cursos de licenciatura em Ciências Biológicas.

\begin{tabular}{|c|c|c|c|c|}
\hline \multirow[t]{3}{*}{ Universidade/ Campi } & \multicolumn{4}{|c|}{ Oferecem disciplina com a temática "Educação Inclusiva" } \\
\hline & Não & & im & \\
\hline & & Obrigatória & $\begin{array}{l}\text { Optativa/ } \\
\text { Eletiva }\end{array}$ & Disciplina \\
\hline $\mathrm{BIO} 1$ & $x$ & & & \\
\hline $\mathrm{BIO} 2$ & $x$ & & & \\
\hline $\mathrm{BIO} 3$ & & & $x$ & $\begin{array}{l}\text { Uma disciplina específica sobre a } \\
\text { temática }\end{array}$ \\
\hline $\mathrm{BIO} 4$ & $x$ & & & \\
\hline $\mathrm{BIO} 5$ & $x$ & & & \\
\hline $\mathrm{BIO} 6$ & $x$ & & & \\
\hline $\mathrm{BIO} 7$ & $x$ & & & \\
\hline $\mathrm{BIO} 8$ & $x$ & & & \\
\hline $\mathrm{BIO} 9$ & $x$ & & & \\
\hline $\mathrm{BIO} 10$ & & $x$ & & $\begin{array}{l}\text { Inserção da temática em uma } \\
\text { disciplina }\end{array}$ \\
\hline $\mathrm{BIO} 11$ & & $x$ & & $\begin{array}{l}\text { Inserção da temática em duas } \\
\text { disciplinas } \\
\text { Uma disciplina específica sobre o } \\
\text { tema }\end{array}$ \\
\hline $\mathrm{BIO} 12$ & $x$ & & & \\
\hline $\mathrm{BIO} 13$ & & $x$ & & $\begin{array}{l}\text { Inserção da temática em três } \\
\text { disciplinas }\end{array}$ \\
\hline
\end{tabular}


Revista Tecné, Episteme y Didaxis: TED. Año 2014, Número Extraordinario. ISSN Impreso: 0121-3814, ISSN web: 2323-0126

Memorias, Sexto Congreso Internacional sobre Formación de Profesores de Ciencias. 08 al 10 de octubre de 2014, Bogotá

Dos nove cursos de licenciatura em Física, quatro possuem disciplina que abordam a temática "Educação Inclusiva", sendo que em FIS 3 e FIS 8, as disciplinas são optativas, e em FIS 4 e FIS 7, as disciplinas são obrigatórias (Quadro 02)

Quadro 02: Relação da oferta de disciplinas com a temática "Educação Inclusiva" nos cursos de licenciatura em Física.

\begin{tabular}{|c|c|c|c|c|}
\hline \multirow[t]{3}{*}{ Universidade/ Campi } & \multicolumn{4}{|c|}{ Oferecem disciplina com a temática "Educação Inclusiva" } \\
\hline & Não & \multicolumn{2}{|c|}{ Sim } & \\
\hline & & Obrigatória & $\begin{array}{l}\text { Optativa/ } \\
\text { Eletiva }\end{array}$ & Nome da disciplina \\
\hline FIS 1 & $X$ & & & \\
\hline FIS 2 & $\mathrm{X}$ & & & \\
\hline FIS 3 & & & $x$ & $\begin{array}{l}\text { Uma disciplina específica sobre a } \\
\text { temática }\end{array}$ \\
\hline FIS 4 & & $\mathrm{X}$ & & $\begin{array}{l}\text { Inserção da temática em uma } \\
\text { disciplina }\end{array}$ \\
\hline FIS 5 & $\mathrm{X}$ & & & \\
\hline FIS 6 & $X$ & & & \\
\hline FIS 7 & & $x$ & & $\begin{array}{l}\text { Inserção da temática em uma } \\
\text { disciplina }\end{array}$ \\
\hline FIS 8 & & & $X$ & $\begin{array}{l}\text { Inserção da temática em uma } \\
\text { disciplina }\end{array}$ \\
\hline FIS 9 & $X$ & & & \\
\hline
\end{tabular}

Por fim, dos oito cursos de licenciatura em Química, apenas dois contam com disciplinas que abordam a temática "Educação Inclusiva". Em QUIM 6, são três disciplinas obrigatórias e em QUIM 7, uma disciplina optativa (Quadro 03). 
Revista Tecné, Episteme y Didaxis: TED. Año 2014, Número Extraordinario. ISSN Impreso: 0121-3814, ISSN web: 2323-0126

Memorias, Sexto Congreso Internacional sobre Formación de Profesores de Ciencias. 08 al 10 de octubre de 2014, Bogotá

Quadro 03: Relação da oferta de disciplinas com a temática "Educação Inclusiva" nos cursos de licenciatura em Química.

\begin{tabular}{|c|c|c|c|c|}
\hline \multirow[t]{3}{*}{ Universidade/ Campi } & \multicolumn{4}{|c|}{ Oferecem disciplina com a temática "Educação Inclusiva" } \\
\hline & Não & & sim & \\
\hline & & Obrigatória & $\begin{array}{l}\text { Optativa/ } \\
\text { Eletiva }\end{array}$ & Nome da disciplina \\
\hline QUIM 1 & $x$ & & & \\
\hline QUIM 2 & $x$ & & & \\
\hline QUIM 3 & $x$ & & & \\
\hline QUIM 4 & $x$ & & & \\
\hline QUIM 5 & $x$ & & & \\
\hline QUIM 6 & & $x$ & & $\begin{array}{l}\text { Inserção da temática em duas } \\
\text { disciplinas } \\
\text { Uma disciplina específica sobre } \\
\text { o tema }\end{array}$ \\
\hline QUIM 7 & & & $x$ & $\begin{array}{l}\text { Uma disciplina específica sobre } \\
\text { o tema }\end{array}$ \\
\hline QUIM 8 & $x$ & & & \\
\hline
\end{tabular}

As disciplinas que inserem a temática "Educação Inclusiva", de um modo geral, o fazem como um tópico em seu conteúdo programático, com o objetivo de refletir sobre os pressupostos e processos de inclusão dos alunos com NEE. São disciplinas de Didática, Psicologia da Educação e/ou Políticas Educacionais Brasileiras (os nomes variam de acordo com a universidade).

Já as disciplinas específicas sobre a temática "Educação Inclusiva" são disciplinas voltadas totalmente para o ensino de alunos com NEE. Entretanto, são disciplinas que focam uma deficiência como, por exemplo, a disciplina de Libras, que tem por objetivo discutir a educação dos surdos. 
Revista Tecné, Episteme y Didaxis: TED. Año 2014, Número Extraordinario. ISSN Impreso: 0121-3814, ISSN web: 2323-0126

Memorias, Sexto Congreso Internacional sobre Formación de Profesores de Ciencias. 08 al 10 de octubre de 2014, Bogotá

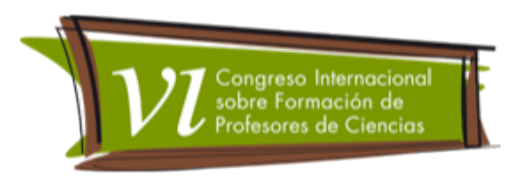

\section{Conclusões}

A formação de inicial de professores deveria atender às necessidades e aos desafios da atualidade (Pletsch, 2009), entretanto, como apresentado anteriormente, nem os PPPs, nem os PEs dos cursos de licenciatura em Ciências tratam da temática "Educação Inclusiva" de modo sistemático.

É na formação inicial que o professor irá adquirir fundamentos para lidar com as diferentes necessidades de aprendizagem de cada aluno, inclusive os alunos com NEE (Vilela-Ribeiro \& Benite, 2010).

Logo, o desafio dos cursos de formação inicial de professores é "produzir conhecimentos que possam desencadear novas atitudes que permitam a compreensão de situações complexas de ensino, para que os professores possam desempenhar de maneira responsável e satisfatória seu papel de ensinar e aprender para a diversidade" (Pletsch, 2009, pág.148-149).

O professor é a peça chave, é o eixo para que a educação inclusiva tenha sucesso nas escolas e, para que isso ocorra, são necessárias mudanças nos currículos dos cursos de licenciatura, em especial, dos cursos de licenciatura em Ciências, para que o professor possa se sentir preparado para receber em sua sala de aula os alunos com NEE.

\section{Referências Bibliográficas}

BIO 13 (2013). Projeto Político Pedagógico - Curso de Licenciatura em Ciências da Natureza. Escola de Artes, Ciências e Humanidades: São Paulo.

Brasil. (1990). Declaração Mundial sobre Educação para todos: plano de ação para satisfazer as necessidades básicas de aprendizagem. UNESCO, Jomtiem/Tailândia.

Brasil. (1994a). Declaração de Salamanca e linha de ação sobre necessidades educativas especiais. Brasília: UNESCO.

Brasil. (1994b). Política Nacional de Educação Especial. Brasília: MEC.

Brasil. (2001). Diretrizes nacionais para a educação especial na educação básica. Brasília: MEC.

Brasil (2008). Política Nacional de Educação Especial na Perspectiva da 
Revista Tecné, Episteme y Didaxis: TED. Año 2014, Número Extraordinario. ISSN Impreso: 0121-3814, ISSN web: 2323-0126

Memorias, Sexto Congreso Internacional sobre Formación de Profesores de Ciencias. 08 al 10 de octubre de 2014, Bogotá

Educação Inclusiva. Brasília: MEC.

INEP, 2013. Acessado em 06/05/2013. Disponível em <http://portal.inep.gov.br/basica-censo>

Lüdke, M.; André, M.E.D.A. (1986). Pesquisa em Educação: abordagens qualitativas. São Paulo: EPU.

Mizukami, M.G.N. et al. (2010). Escola e aprendizagem da docência: processos de investigação e formação. São Carlos: EdUFSCar.

Pletsch, M.D. (2009). A formação de professores para a educação inclusiva: legislação, diretrizes políticas e resultados de pesquisas. Educar, 33, pág. 143156.

Prieto, R.G. (2006). Atendimento escolar de alunos com necessidades educacionais especiais: um olhar sobre as políticas públicas de educação no Brasil. In: ARANTES, V.A. (org.) Inclusão escolar: pontos e contrapontos. São Paulo: Summus, pág. 31-73

QUIM 6 (2013). Projeto Político Pedagógico - Curso de Licenciatura em Química. Faculdade de Filosofia, Ciências e Letras: Ribeirão Preto.

Rinaldi, R.P.; Reali, A.M.M.R.; Costa, M.P.R. (2009). Formação de professores e Educação Especial: Análise de um processo. In: Costa, M.P.R. (org.). Educação Especial: aspectos conceituais e emergentes. São Carlos: EdUFSCar, pág.151 - 166.

Vilela-Ribeiro, E.B.; Benite, A.M.C. (2010). A educação inclusiva na percepção dos professores de Química. Ciência \& Educação, 16(3), pág. 585-594. 